\title{
BMJ Open Differences between frequent emergency department users in a secondary rural hospital and a tertiary suburban hospital in central Japan: a prevalence study
}

\author{
Makoto Kaneko (D , , ${ }^{1,2}$ Machiko Inoue, ${ }^{1,2}$ Masashi Okubo, ${ }^{3}$ Allison K Cullen Furgal, ${ }^{4}$ \\ Benjamin F Crabtree, ${ }^{5}$ Michael D Fetters ${ }^{6}$
}

To cite: Kaneko M, Inoue M, Okubo M, et al. Differences between frequent emergency department users in a secondary rural hospital and a tertiary suburban hospital in central Japan: a prevalence study. BMJ Open 2020;10:e039030. doi:10.1136/ bmjopen-2020-039030

- Prepublication history for this paper is available online. To view these files, please visit the journal online (http://dx.doi. org/10.1136/bmjopen-2020039030).

Received 01 April 2020

Revised 22 July 2020

Accepted 23 July 2020

Check for updates

(C) Author(s) (or their employer(s)) 2020. Re-use permitted under CC BY-NC. No commercial re-use. See rights and permissions. Published by BMJ.

For numbered affiliations see end of article.

Correspondence to Dr Makoto Kaneko; kanekom@yokohama-cu.ac.jp

\section{ABSTRACT}

Objectives Although frequent emergency department (ED) use is a global issue, little research has been conducted in a country like Japan where universal health insurance is available. The study aims to (1) document the proportion of ED visits that are by frequent users and (2) describe the differences in characteristics of frequent $E D$ users and other ED users including expenditures between a secondary and a tertiary hospital.

Design A prevalence study for a period of 1 year.

Setting A secondary hospital and a tertiary hospital in central Japan.

Participants All patients who presented to the EDs. Primary outcome measures We defined frequent ED user as a patient who visited the $E D \geq 5$ times/year. The main outcome measures were the proportion of frequent ED users among all ED users and the proportion of healthcare expenditures by the frequent ED users among all ED expenditures.

Results Of 25231 ED visits over 1 year, 134 frequent ED users accounted for 1043 visits - $0.66 \%$ of all ED users, comprised $4.1 \%$ of all ED visits, and accounted for $1.9 \%$ of total healthcare expenditures. Median ED visits per one frequent ED user was 7.9. At the patient level, after adjusting for age, gender and receiving public assistance, older age (OR 1.01, 95\% Cl: 1.00 to 1.02) and receiving public assistance (OR 7.19, 95\% $\mathrm{Cl} 2.87$ to 18.07 ) had an association with frequent ED visits. At the visit-level analysis, evaluation by internal medicine (OR 1.27, 95\% Cl 1.02 to 1.57), psychiatry (OR $124.69,95 \% \mathrm{Cl} 85.89$ to 181.01) and obstetrics/gynaecology (OR $2.77,95 \% \mathrm{Cl} 2.09$ to 3.67) were associated with frequent ED visits.

Conclusion The proportion of frequent ED users, of total visits, and of expenditures attributable to them-while still in the low end of the distribution of published ranges - are lower in this study from Japan than in reports from many other countries.

\section{INTRODUCTION}

Frequent emergency department (ED) use is associated with higher mortality rates ${ }^{1}$ and financial burden. ${ }^{2}$ In a previous systematic
Strengths and limitations of this study

- This study was an exhaustive investigation that evaluated all emergency department (ED) visitors over 1 year in the two hospitals. Including the entire population of eligible individuals precludes the need for inferential statistics and inherent risks of extrapolation had only a sample of eligible participants been chosen for investigation.

- The study evaluated not only the numbers of visits but also the healthcare expenditures of frequent $E D$ visitors.

- This study only included one secondary hospital and one tertiary hospital.

- This study did not assess for the severity of condition or diseases of the participants.

review, frequent ED users comprised $0.1 \%$ $50 \%$ of all ED users and accounted for $1.9 \%-20.5 \%$ of all ED visits in the USA. ${ }^{3}$ Also, the top $20 \%$ of frequent ED users account for $84 \%$ of all healthcare expenditures and 'hot spots' have been identified where many frequent ED users live. ${ }^{4} \mathrm{~A}$ study by Gross and colleagues published in 2013 demonstrated that interventions for individual frequent ED users or hot spots by multidisciplinary teams (such as family physicians, nurses, care managers and administrative officers) are associated with a reduction of the number of ED visits and expenditures. ${ }^{4}$ Similarly, in three regions in the USA, multidisciplinary team interventions decreased hospitalisation rates by $34 \%$ and healthcare expenditures by 1.2 million dollars. ${ }^{5}$ However, a recent clinical trial examining the effect of complex care transition programmes using a multidisciplinary team found no significant differences in hospital readmission between the intervention and control groups. ${ }^{6}$ High rates of 
frequent ED users have been reported in North America, Europe and Oceania. ${ }^{7}$ In Asian countries, frequent ED users in Taiwan comprised $3.5 \%$ of all ED users and accounted for $14.3 \%$ of all ED visits. ${ }^{8}$ In Korea, $3.1 \%$ of all ED visitors were frequent ED users and occupied $14.0 \%$ of total ED visits. ${ }^{9}$ Among frequent ED users, low socioeconomic status and mental health problems are known predictors of frequent ED use based on research in nine countries. ${ }^{710}$ Although such studies about frequent ED use were conducted, research on frequent ED use is little in countries with well-developed comprehensive national health insurance such as Japan.

In Japan, research on frequent ED users has been investigated in single-centre studies. ${ }^{11}{ }^{12}$ Also, there is no research about healthcare expenditure of frequent ED users in Japan. For example, in the study by Takeuchi et al, they found frequent ED users comprised $1.4 \%$ of all ED users and occupied $6.8 \%$ of all ED visits. ${ }^{11}$ Frequent ED users were older and more often receiving governmental welfare in comparison with non-frequent ED users. ${ }^{11}$ As the number of ED visits by ambulances has been annually increasing by 72 thousand per year in Japan, ${ }^{13}$ a better understanding of the patterns and costs associated with frequent ED users in Japan would be indispensable for developing interventions to reduce unnecessary visit burdens on EDs and mitigate unnecessary costs.

Understanding the current status of frequent ED users in Japan could inform policymaking that optimises the use of EDs and leads efficiency in healthcare expenditures. Hence the study aims of this research were to (1) document the proportion of ED visits that are by frequent users and (2) describe the differences in characteristics of frequent ED users and other ED users between a secondary and a tertiary hospital in Japan. We hypothesised that a few frequent ED users would account for the major proportion of all ED users and for significant healthcare expenditure in Japan.

\section{METHODS}

\section{Design}

This study team conducted a prevalence study by using a retrospective chart review for a period of 1 year ranging from 1 January 2017 to 31 December 2017. In the present study, we followed the Strengthening the Reporting of Observational studies in Epidemiology statement. ${ }^{14}$

\section{Setting}

Kikugawa General Hospital (a secondary hospital) and Iwata City Hospital (a tertiary hospital) in central Japan served as the sites for study. The size of these two hospitals is generally comparable with other secondary and tertiary care hospitals in Japan. ${ }^{15}$ Each hospital is the only general public hospital serving the local municipality. The characteristics of these hospitals are described in table 1 . In Japan, secondary hospitals provide emergency care for a patient who potentially requires admission and tertiary hospitals offer intensive care such as acute myocardial infarction, stroke and multiple injury. ${ }^{16}$ The secondary hospital in this study serves a catchment area of about 48000 people but does not provide inpatient care for children due to the lack of paediatricians. It serves as the single public institution providing inpatient care for mental health in this region. Like the majority of hospitals in Japan, nurses triage patients presenting to the ED based on the patient's chief report for evaluation by one of the hospital's subspecialty departments, for example, internal medicine, surgery or psychiatry. This differs from the typical US model of emergency care where nurses triage for acuity of need, but emergency physicians provide the first evaluation of all patients coming to the ED. ${ }^{17}$

\section{Patient and public involvement}

This research was conducted without patient involvement. Patients were not invited to comment on the study design, and they were not consulted in the development of relevant patient outcomes or asked to interpret the

Table 1 Characteristics of the study secondary and tertiary hospitals

\begin{tabular}{|c|c|c|}
\hline Catchment area served & 4800 people & 167000 people \\
\hline Total number of beds & 260 & 500 \\
\hline Total number of emergency department visits & 5914 & 19317 \\
\hline Number of psychiatric beds & $58^{*}$ & 0 \\
\hline Number of beds in the emergency room & 2 & 24 \\
\hline Number of infectious diseases beds & 0 & 2 \\
\hline Number of paediatric beds $\dagger$ & 0 & 20 \\
\hline Proportion of the population aged 65 years and over in the city $(\%)^{36}$ & 25.0 & 26.1 \\
\hline Unemployment rate in the city $(\%)^{36}$ & 2.9 & 3.6 \\
\hline
\end{tabular}

*The secondary hospital is the only public institution for providing inpatient care for mental health in the area.

†The secondary hospital does not provide inpatient care for children due to the lack of paediatricians. 
results. They were not asked to contribute to the writing or editing of this document for readability or accuracy.

\section{Participants}

Inclusion criteria

All patients who presented to the EDs during the study period were eligible for inclusion. There were no exclusion criteria for the study.

\section{Measures}

To be consistent with the previous literature, ${ }^{3}$ we defined a frequent ED user as a patient who visited the ED in the same hospital $\geq 5$ times/year during 2017. The study's main outcome measures were the proportion of the frequent ED users among all ED users and the proportion of healthcare expenditures by the frequent ED users among all ED expenditures. We also counted the frequency of $\mathrm{ED}$ visits (1 time/year, 2-4 times, 5-10 times, 10-14 times and $\geq 15$ ) and explored the characteristics of the frequent ED users by age, gender, receipt of public assistance (governmental welfare), ambulance use, hospitalisation, service of hospitalisation (internal medicine, surgery, orthopaedics, psychiatry, paediatrics and obstetrics/gynaecology) and in-hospital death.

\section{Statistical analysis}

To analyse for differences in the characteristics between the frequent ED users and non-frequent ED users, we used $\chi^{2}$ tests. We employed two multivariable models, changing the units of analyses: patient level and visit level. In the patient-level analysis, we used logistic regression and adjusted age (as a continuous variable), gender (men was the reference group) and receiving public assistance. In the visit-level analysis, we used a mixed-effect model to include a random effect for hospital and individual covariates as fixed effects. We adjusted for use of ambulance, service of evaluation in the ED and hospitalisation. Covariates were selected based on the literature review. ${ }^{78}$ For the statistical analysis, we used Stata V.15 with statistical significance defined by a $p$ value $<0.05$.

\section{RESULTS}

\section{Frequency of visits and expenditures by frequent ED users}

A total of $25231 \mathrm{ED}$ visits were made by 20388 patients (men: 10 746) to the two hospitals during the study period. We did not have missing data for each reported variable. The median age (IQR) was 51 (range 23-75) and the total healthcare expenditure was 3774 million yen $(\fallingdotseq 35.2$ million dollars). Healthcare expenditures in the ED of the secondary hospital totalled 188 million yen ( $\fallingdotseq 1.7$ million dollars) and that of the tertiary hospital totalled 3586 million yen ( $\fallingdotseq 33.0$ million dollars). Of all the visits, there were 134 frequent ED users (men=76). The median of age (IQR) was 61.5 years $(35-80)$ and the total healthcare expenditure was 72 million yen $(\fallingdotseq 0.68$ million dollars). The total number of visits by the frequent ED users was 1043 and these comprised $4.1 \%$ of all ED

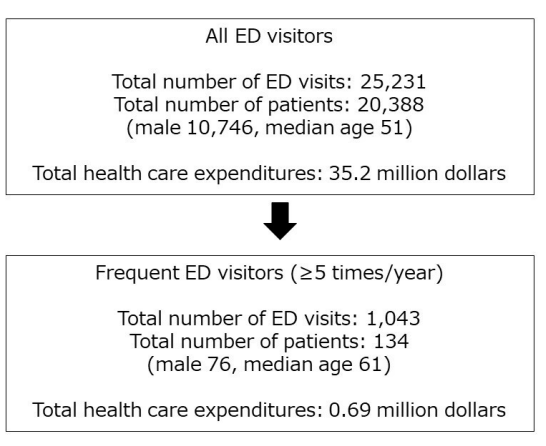

Figure 1 Summary of frequent emergency department (ED) visitors.

visits. Frequent ED users accounted for $0.66 \%$ of all ED users and $1.9 \%$ of total healthcare expenditures. Figure 1 shows summary of the results.

\section{Patient-level analysis}

As shown in table 2, relative to patient-level characteristics of the frequent ED users, the proportions of older adults $(\geq 65)(\mathrm{p}=0.023)$ and the patients receiving public assistance were higher than those of the non-frequent ED users $(p<0.001)$. Gender and in-hospital death were not associated with the frequent ED users. In terms of the visitlevel characteristics of the frequent ED users, the proportion of patients evaluated by psychiatry and obstetrics/ gynaecology was higher than those of the non-frequent ED users (both $\mathrm{p}<0.001$ ). The proportion of the patients among frequent ED users who used an ambulance $(\mathrm{p}<0.001)$, who were admitted to a hospital $(\mathrm{p}=0.006)$ or were evaluated by internal medicine $(\mathrm{p}=0.003)$, surgery $(\mathrm{p}=0.001)$ and orthopaedics $(\mathrm{p}<0.001)$ were lower than those of the non-frequent ED users.

\section{Comparison of the frequent ED user characteristics in the secondary and tertiary hospitals}

\section{Patient-level and visit-level characteristics by number of the ED users}

Tables 3 and 4 illustrate patient-level and visit-level characteristics of ED users according to the number of visits to the secondary and tertiary hospitals, respectively. Although many patients from either hospital used the ED only one time in the study period, four patients (two in the secondary hospital and two in the tertiary hospital) used the ED 16 times or more. For factors such as in-hospital death, receiving public assistance, use of ambulance and hospitalisation, the majority was accounted for by the non-frequent ED users (one to four visits).

Table 5 provides a comparison of frequent ED users' characteristics between the secondary hospital and the tertiary hospital. In the secondary hospital, the proportion of frequent ED users who were evaluated by psychiatry $(\mathrm{p}<0.001)$ and obstetrics/gynaecology $(\mathrm{p}<0.001)$ was higher than those in the tertiary hospital. In the tertiary hospital, the proportion of patients who were aged 14 years and younger $(p<0.004)$, evaluated by internal 
Table 2 Comparison of frequent and non-frequent ED users for both the secondary and tertiary hospitals

\begin{tabular}{|c|c|c|c|c|}
\hline & Total & $\begin{array}{l}\text { Frequent } \\
\text { ED users }\end{array}$ & $\begin{array}{l}\text { Non-frequent } \\
\text { ED users }\end{array}$ & $P$ value \\
\hline \multicolumn{5}{|c|}{ Patient level $n=20388$ (number of patients) } \\
\hline \multicolumn{5}{|c|}{ Age } \\
\hline $14<$ & 3728 & 19 & 3709 & 0.217 \\
\hline $15-64$ & 8862 & 51 & 8811 & 0.205 \\
\hline $65 \geq$ & 7798 & 64 & 7734 & $0.023^{*}$ \\
\hline \multicolumn{5}{|l|}{ Gender } \\
\hline Male & 9642 & 58 & 9584 & 0.351 \\
\hline Female & 10746 & 76 & 10670 & \\
\hline \multicolumn{5}{|l|}{ In-hospital death } \\
\hline No & 19825 & 131 & 19694 & 0.771 \\
\hline Yes & 563 & 3 & 560 & \\
\hline \multicolumn{5}{|c|}{ Receiving public assistance } \\
\hline No & 20257 & 128 & 20129 & $<0.001^{*}$ \\
\hline Yes & 110 & 5 & 105 & \\
\hline \multicolumn{5}{|c|}{ Visit level n=25 231 (number of visits) } \\
\hline \multicolumn{5}{|c|}{ Use of ambulance } \\
\hline No & 18496 & 834 & 17662 & $<0.001^{*}$ \\
\hline Yes & 6735 & 209 & 6526 & \\
\hline \multicolumn{5}{|l|}{ Hospitalisation } \\
\hline No & 20256 & 872 & 19384 & $p=0.006^{*}$ \\
\hline Yes & 4975 & 171 & 4804 & \\
\hline \multicolumn{5}{|c|}{ Results of triage in the ED } \\
\hline Internal medicine & 11762 & 439 & 11323 & $p=0.003^{*}$ \\
\hline Surgery & 1312 & 30 & 1282 & $\mathrm{p}=0.001^{*}$ \\
\hline Orthopaedics & 4412 & 84 & 4328 & $<0.001^{\star}$ \\
\hline Psychiatry & 236 & 189 & 47 & $<0.001^{*}$ \\
\hline Paediatrics & 2817 & 98 & 2719 & $\mathrm{p}=0.064$ \\
\hline OB/GYN & 1181 & 95 & 1086 & $<0.001$ \\
\hline
\end{tabular}

ED, emergency department; OB/GYN, obstetrics/gynaecology.

medicine $(p<0.001)$, paediatrics $(p<0.001)$ and surgery $(\mathrm{p}<0.001)$, was higher than those in the tertiary hospital.

After adjusting for age, gender, and receiving public assistance, older age (OR 1.01, 95\% CI: 1.00 to 1.02 , $\mathrm{p}=0.004)$ and receiving public assistance (OR 7.19, 95\% CI 2.87 to $18.07, \mathrm{p}<0.001$ ) were associated with frequent $\mathrm{ED}$ visits at the patient level. In the visit-level analysis, evaluation by internal medicine (OR 1.27, 95\% CI: 1.02 to $1.57, \mathrm{p}=0.032$ ), psychiatry (OR 124.69 , 95\% CI 85.89 to 181.01, p<0.001) and obstetrics/gynaecology (OR $2.77,95 \%$ CI 2.09 to $3.67, \mathrm{p}<0.001$ ) had associations with frequent ED visits. Ambulance use (OR 0.81, 95\% CI 0.69 to $0.95, \mathrm{p}=0.011$ ) and evaluation by orthopaedics (OR $0.63,95 \%$ CI 0.47 to $0.84, p=0.002$ ) were negatively associated with frequent ED visits. The details of the results are shown in the online supplementary file.

\section{DISCUSSION}

Proportion of frequent ED users and health care expenditures

These combined findings from a tertiary hospital and secondary hospital in a largely urban area found that less than $1 \%$ of ED users $(0.66 \%)$ accounted for nearly 1 in 25 visits $(4.1 \%)$ and nearly $1.9 \%$ of healthcare expenditures. These findings contrast with the previous Japanese study conducted near Tokyo where $1.39 \%$ frequent ED users ( $\geq 4$ visits/year) occupied $6.75 \%$ of all ED visits and the previous study did not report the used healthcare expenditures. ${ }^{11}$ The differences may be attributable to a different setting as the latter is from an ED in a single tertiary hospital serving a population of 170000 near metropolitan Tokyo. Because this tertiary hospital was located near a metropolitan area, the patients might visit the hospital from a wider range of areas compared with 
Table 3 The patient-level and visit-level characteristics of ED users based on the number of visits in the secondary hospital

\begin{tabular}{|c|c|c|c|c|c|c|}
\hline Number of ED visits & 1 & $2-4$ & $5-7$ & $8-10$ & $11-15$ & $16 \geq$ \\
\hline \multicolumn{7}{|c|}{ Patient level Number of patients (\%): $n=4760$} \\
\hline \multicolumn{7}{|c|}{ Age } \\
\hline $14<$ & $439(91.6)$ & $38(7.9)$ & $1(0.2)$ & $1(0.2)$ & $0(0)$ & $0(0)$ \\
\hline $15-64$ & $1879(86.8)$ & $267(12.3)$ & $11(0.5)$ & $6(0.3)$ & $0(0)$ & $2(0.1)$ \\
\hline $65 \geq$ & $1670(78.9)$ & $426(20.1)$ & $18(0.9)$ & $1(0)$ & $1(0)$ & $0(0)$ \\
\hline \multicolumn{7}{|l|}{ Gender } \\
\hline Female & $2094(85.2)$ & $341(13.9)$ & $18(0.7)$ & $3(0.1)$ & $0(0)$ & $1(0)$ \\
\hline \multicolumn{7}{|l|}{ In-hospital death } \\
\hline No & $3832(83.3)$ & $727(15.8)$ & $30(0.7)$ & $8(0.2)$ & $1(0)$ & $2(0)$ \\
\hline Yes & $156(97.5)$ & $4(2.5)$ & $0(0)$ & $0(0)$ & $0(0)$ & $0(0)$ \\
\hline \multicolumn{7}{|c|}{ Receiving public assistance } \\
\hline \multicolumn{7}{|l|}{ Use of ambulance } \\
\hline No & $2921(63.7)$ & $300(28.4)$ & $138(3.0)$ & $44(0.1)$ & $13(0.3)$ & $169(3.7)$ \\
\hline Yes & $1068(69.5)$ & $399(26.0)$ & $33(2.1)$ & $28(1.8)$ & $1(0)$ & $8(0.5)$ \\
\hline \multicolumn{7}{|l|}{ Hospitalisation } \\
\hline No & $3052(65.0)$ & $1264(26.9)$ & $127(2.7)$ & $66(1.4)$ & $8(0.2)$ & $175(3.7)$ \\
\hline Yes & $937(65.5)$ & $435(30.4)$ & $44(3.1)$ & $6(0.4)$ & $6(0.4)$ & $2(0.1)$ \\
\hline
\end{tabular}

$E D$, emergency department.

Table 4 The patient-level and visit-level characteristics of ED users based on the number of visits in the tertiary hospital

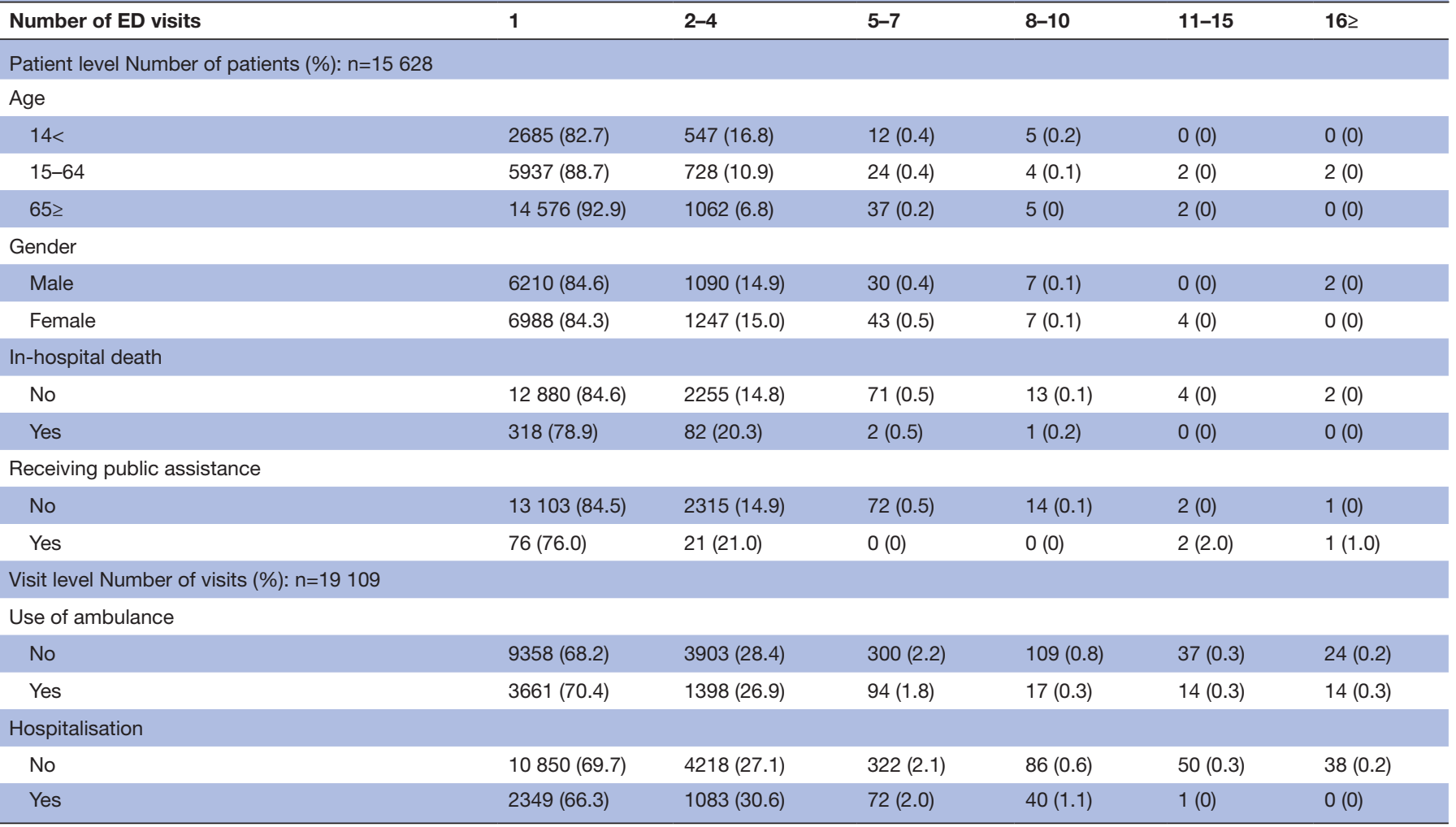

ED, emergency department. 
Table 5 Differences in frequent ED users' characteristics between secondary and tertiary hospitals

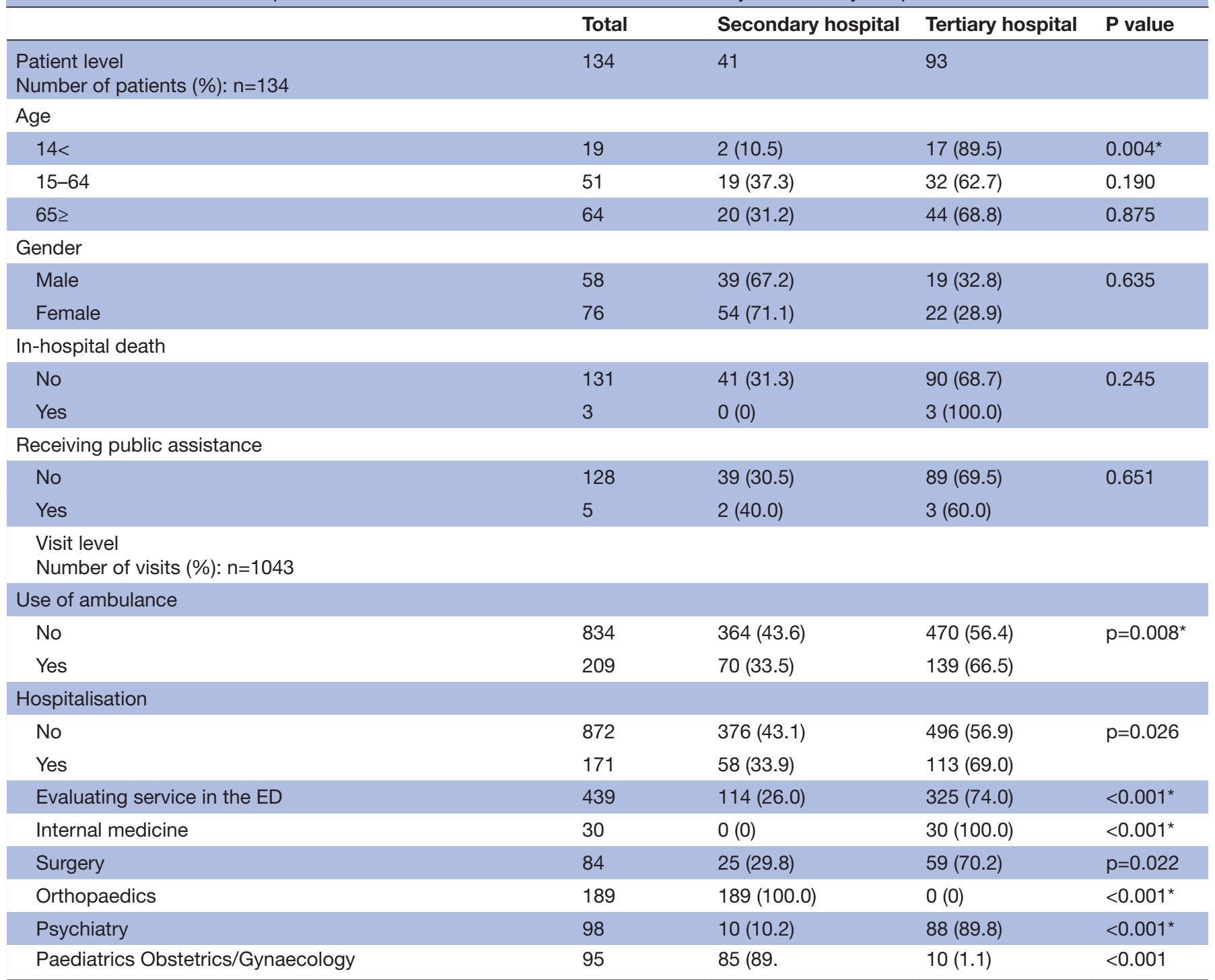

ED, emergency department.

the present study's setting. The proportions of frequent ED users in both Japanese studies were less by a half to a quarter than the ranges from countries described in a systematic review (frequent ED users: $4.5 \%-8 \%$ of all ED users). The ED visits of frequent users are roughly a third to a tenth less than other countries $(21 \%-28 \%$ of all ED visits). ${ }^{7}$ Compared with the Asian countries in the previous literature, the proportion of frequent ED visits was almost one-third in Japan. ${ }^{89}$ In a previous US study, $1 \%$ of ED users accounted for $29 \%$ of costs ${ }^{4}$-a stark contrast to just less than $1 \%$ of ED users in the current study accounting for about $2 \%$ of expenditures. In addition, the proportion of the healthcare expenditures by frequent ED users from both studies in Japan is much lower than found in several previous studies in the USA. ${ }^{4} 1819$

As reported in an international literature review, the problem of frequent ED visits has been observed in multiple countries including Asian countries. ${ }^{7}$
Multidisciplinary interventions such as case management, care plan and information sharing have been found to be effective to reduce the frequent ED users. ${ }^{2}{ }^{20}$ Kaigo Hoken, Japan's long-term care insurance programme was introduced to provide long-term care support for older adults since 2000. ${ }^{21}$ Under Kaigo Hoken, care managers coordinate multiple care services for older adults. ${ }^{21}$ The care management financed under Kaigo Hoken may contribute to the low proportion of frequent ED users in the study compared with other international settings due to proactive care for limitations in activities of daily living. This support can also help mitigate social problems. Also, free access and universal healthcare coverage in Japan may contribute to the results as well. Patients can access healthcare services regardless of their income, living place and types of hospitals. ${ }^{21}$ In Japan, patients tend to visit physician's office and a hospital outpatient clinic in a more timely manner, compared with those in the USA. ${ }^{22} 23$ 


\section{Characteristics of the frequent ED users}

Characteristics of the frequent ED users found in the current study, older age, low socioeconomic status and mental health problems, are consistent with previous studies in other countries. ${ }^{324}$ For example, findings from the UK, USA, Canada and Taiwan similarly identified older age ${ }^{25}$ and mental problems. ${ }^{742627}$ In our study, the proportion of patients who were older than or equal to 65 years among all ED visitors was $38.2 \%$. This is relatively higher than those in the previous studies in other countries such as $16.6 \%-22.1 \%$ (USA), ${ }^{28} 2925.1 \%$ (Canada) ${ }^{30}$ and $34.5 \%$ (Taiwan). ${ }^{8}$ Therefore, older patients could not explain the low rate of frequent ED users in our study. Thus, as we discussed above, the Japanese healthcare systems such as Kaigo Hoken or universal healthcare coverage could explain our results. While previous studies have also identified homelessness ${ }^{24}$ and substance abuse $^{72630}$ as predictors for frequent ED use, the rate of homelessness in Japan is very low compared with the USA, $0.004 \%$ versus $0.17 \%,{ }^{31} 32$ and substance abuse also is very low: for example, $0.5 \%$ versus $4.9 \%$ in use of methamphetamine and $0.3 \%$ versus $14.3 \%$ in use of cocaine. ${ }^{33}$ Thus, it was not surprising for these factors not to be predictors of frequent ED use.

In the previous study conducted in Japan, mental health issues were not related to frequent $\mathrm{ED}$ visits but this may be attributable to the absence of full-time psychiatric providers in that hospital. ${ }^{11}$ While a difference was noted in the proportion of frequent ED visits for paediatric problems between the secondary and tertiary hospital, this finding was not surprising given the lack of a full-time paediatrician in the secondary hospital in our study. Because characteristics of frequent ED users are heterogeneous, ${ }^{7}$ analysis of characteristics of frequent ED users in each hospital is important to reduce frequent ED visits. For example, case management including insurance coverage and access to support services has been shown to reduce ED visits among low-income adults. ${ }^{34}$ Moreover, multidisciplinary intervention with mental health and substance-abuse professionals decrease ED visits and healthcare cost. ${ }^{35}$ These factors, namely, low socioeconomic status and mental issues, are of particular importance for attention of healthcare providers and policymakers seeking to develop effective interventions to reduce unnecessary visits and reduce costs.

Future research could include a multicentre or nationwide study in Japan to further characterise frequent ED users across the nation. Despite the much lower rate of frequent ED users, visits and associated costs in our study compared with other countries, research in Japan on the potential benefit of intervening with a multidisciplinary team emerges as an area ripe for future research.

\section{Study strengths}

This is the first study to investigate healthcare expenditures for frequent ED users in Japan. Also, this is the first study comparing the characteristics of frequent ED users in a secondary and a tertiary hospital. A possible explanation for the low proportion of frequent ED users could come from inadequate accounting for the actual number of ED visits. In the current study, we counted ED visits in each hospital. If patients attended multiple EDs, it is possible that we would not capture the actual number of ED visits and underestimate the total number of frequent ED users. However, this seems unlikely to have a substantial impact as both hospitals serve as the primary hospitals in their catchment areas.

\section{Study limitations}

First, because this study only included one secondary hospital and one tertiary hospital, the results need to be confirmed through examination of other Japanese hospitals. Both studies occurred in a single prefecture, which is predominantly rural. While not necessarily reflective of major metropolitan areas in Japan such as Tokyo, the prefecture of Shizuoka is probably similar to a majority of other prefectures in Japan which have a predominance of rural areas dotted with a few larger cities with tertiary care hospitals. Second, this study did not assess for the severity of condition or diseases of the participants. Thus, appropriateness of the ED visits was not evaluated directly.

\section{CONCLUSION}

The proportion of frequent ED users, of total visits, and of expenditures attributable to them are lower in this study from Japan than the distribution of published ranges in reports from many other countries. Future research on a larger scale will be required to determine if these lower rates are consistent across Japan and to fully explain these differences and understand potential lessons for other countries.

\section{Author affiliations}

${ }^{1}$ Department of Family and Community Medicine, Hamamatsu University School of Medicine, Hamamatsu, Shizuoka, Japan

${ }^{2}$ Shizuoka Family Medicine Program, Kikugawa, Shizuoka, Japan

${ }^{3}$ Department of Emergency Medicine, University of Pittsburgh, Pittsburgh,

Pennsylvania, USA

${ }^{4}$ Department of Family Medicine, University of Michigan Medical School, Ann Arbor, Michigan, USA

${ }^{5}$ Department of Family Medicine and Community Health, Research Division, Rutgers Robert Wood Johnson Medical School, Piscataway, New Jersey, USA

${ }^{6}$ Mixed Methods Program and Department of Family Medicine, University of Michigan Medical School, Ann Arbor, Michigan, USA

Acknowledgements We appreciate the assistance of Dr Hajime Futami and Yuko Okada of Kikugawa General Hospital, Dr Masahiko Terada and Naoki Ohta of Iwata City Hospital. We also thank Dr Koichiro Gibo for his warm support. We would like to thank Editage (www.editage.com) for English language editing.

Contributors MK designed the study and participated in the implementation, data collection, data analysis and writing of the manuscript. MK also served as the guarantor. Ml, MO, BFC and MDF contributed to the design of the study and critically reviewed the manuscript. MK and AKCF analysed the data. All authors had full access to the data and take responsibility for the integrity and accuracy of the analyses.

Funding This study was supported by a Grant-in-Aid for Research Activity Start-up (19K21449). The study's sponsor had no role in the study design, data collection, analysis, interpretation, writing of the report or the decision to submit this article for publication.

Competing interests None declared.

Patient consent for publication Not required. 
Ethics approval This study was approved by the Research Ethics Committee of Hamamatsu University School of Medicine (approval number 18-061), Kikugawa General Hospital and Iwata City Hospital. We were not required to obtain individual informed consent from the patients included in the study. However, the research team displayed a poster in the waiting room of the hospitals to provide information about the collection and use of data for this research, and about the protection of personal information.

Provenance and peer review Not commissioned; externally peer reviewed.

Data availability statement No data are available. Data sharing is not applicable because we did not receive informed consent concerning data sharing from the participants.

Open access This is an open access article distributed in accordance with the Creative Commons Attribution Non Commercial (CC BY-NC 4.0) license, which permits others to distribute, remix, adapt, build upon this work non-commercially, and license their derivative works on different terms, provided the original work is properly cited, appropriate credit is given, any changes made indicated, and the use is non-commercial. See: http://creativecommons.org/licenses/by-nc/4.0/.

\section{ORCID iD}

Makoto Kaneko http://orcid.org/0000-0002-4581-8274

\section{REFERENCES}

1 Moe J, Kirkland S, Ospina MB, et al. Mortality, admission rates and outpatient use among frequent users of emergency departments: a systematic review. Emerg Med J 2016;33:230-6.

2 Soril LJJ, Leggett LE, Lorenzetti DL, et al. Reducing frequent visits to the emergency department: a systematic review of interventions. PLoS One 2015;10:e0123660-18.

3 Scott J, Strickland AP, Warner K, et al. Frequent callers to and users of emergency medical systems: a systematic review. Emerg Med J 2014;31:684-91.

4 Gross K, Brenner JC, Truchil A, et al. Building a citywide, all-payer, hospital claims database to improve health care delivery in a lowincome, urban community. Popul Health Manag 2013;16:S-20-S-25.

5 Warning W, Wood J, Letcher A, et al. Working with super-utilizer population: the experience and recommendations. Super utilizer population: Recommendations of five South Central Pennsylvania High Utilizer. http://www.aligning4healthpa.org/pdf/High_Utilizer_ report.pdf. (accessed March 1, 2020)

6 Finkelstein A, Zhou A, Taubman S, et al. Health Care Hotspotting - A Randomized, Controlled Trial. N Engl J Med 2020;382:152-62.

7 LaCalle E, Rabin E. Frequent users of emergency departments: the myths, the data, and the policy implications. Ann Emerg Med 2010;56:42-8.

8 Huang J-A, Tsai W-C, Chen Y-C, et al. Factors associated with frequent use of emergency services in a medical center. $J$ Formos Med Assoc 2003;102:222-8.

9 Woo JH, Grinspan Z, Shapiro J, et al. Frequent users of hospital emergency departments in Korea characterized by claims data from the National health insurance: a cross sectional study. PLoS One 2016;11:e0147450.

10 Krieg C, Hudon C, Chouinard M-C, et al. Individual predictors of frequent emergency department use: a scoping review. BMC Health Serv Res 2016;16:594.

11 Takeuchi S, Funakoshi $\mathrm{H}$, Nakashima Y, et al. Unique characteristics of frequent presenters to the emergency department in a Japanese population: a retrospective analysis. Acute Med Surg 2019;6:145-51.

12 Ikeda K, Harada T, Tarumi Y, et al. Association between public assistance and frequent emergency department visits in urban areas of Japan: a case-control study. Showa Univ J Med Sci 2020;32:73-80.

13 Ministry of Internal Affairs and Communication. A summary of current status of emergency rescue 2016, 2016. Available: http://www. fdma.go.jp/neuter/topics/houdou/h28/12/281220_houdou_2.pdf [Accessed 1 Mar 2020].
14 von Elm E, Altman DG, Egger M, et al. The strengthening the reporting of observational studies in epidemiology (STROBE) statement: guidelines for reporting observational studies. Ann Intern Med 2007:147:573-7.

15 Ministry of Health, Labor and Welfare. A current status and a challenge of emergency medicine, 2000. Available: https://www. mhlw.go.jp/content/10802000/000328610.pdf [Accessed 1 Mar 2020].

16 Ministry of Health, Labor and Welfare. A current situation of emergency medicine, 2013. Available: http://www.mhlw.go.jp/stf/ shingi/2r9852000002umg2-att/2r9852000002ummz.pdf [Accessed 1 Mar 2020].

17 Hibino S, Hori S. Emergency medicine in the US and the US model emergency medicine in Japan. Nihon Kyukyu Igakukai Zasshi 2010;21:925-34.

18 U.S. Department of Health and Human Services. The high concentration of U.S. health care expenditures, 2006. Available: https://meps.ahrq.gov/data_files/publications/ra19/ra19.pdf [Accessed 1 Mar].

19 Billings J, Raven MC. Dispelling an urban legend: frequent emergency department users have substantial burden of disease. Health Aff 2013;32:2099-108.

20 Moe J, Kirkland SW, Rawe E, et al. Effectiveness of interventions to decrease emergency department visits by adult frequent users: a systematic review. Acad Emerg Med 2017;24:40-52.

21 Sakamoto H, Rahman M, Nomura S, et al. Japan health system review. World Heal Organ Reg Off South-East Asia 2018;8

22 Fukui T, Rhaman M, Takahashi M, et al. The ecology of medical care in Japan. JMAJ 2005;48:163-7.

23 Green LA, Fryer GE, Yawn BP, et al. The ecology of medical care revisited. N Engl J Med 2001;344:2021-5.

24 Doran KM, Raven MC, Rosenheck RA. What drives frequent emergency department use in an integrated health system? national data from the Veterans health administration. Ann Emerg Med 2013;62:151-9.

25 Chi CH, Lee HL, Wang SM, et al. Characteristics of repeated ambulance use in an urban emergency medical service system. $J$ Formos Med Assoc 2001;100:14-19.

26 Broxterman K, Sapien R, Fullerton L, et al. Repeat ambulance use by pediatric patients. Acad Emerg Med 2000;7:36-41.

27 Hays D, Penprase B, Kridli S. Risk factors for frequent users of the emergency department among adults aged 55 and older. J Nurs Educ Pract 2018;8:96-101.

28 Hunt KA, Weber EJ, Showstack JA, et al. Characteristics of frequent users of emergency departments. Ann Emerg Med 2006;48:1-8.

29 Knowlton A, Weir BW, Hughes BS, et al. Patient demographic and health factors associated with frequent use of emergency medical services in a midsized City. Acad Emerg Med 2013;20:1101-11.

30 Doupe MB, Palatnick W, Day S, et al. Frequent users of emergency departments: developing standard definitions and defining prominent risk factors. Ann Emerg Med 2012;60:24-32.

31 Ministry of Health, Labor and Welfare. Nationwide survey of approximate number of homeless people, 2018. Available: https:// www.mhlw.go.jp/content/12003000/000330962.pdf [Accessed 1 Mar 2020].

32 US Department of Housing and Urban Development. The 2018 annual homeless assessment report (AHAR) to Congress, 2018. Available: https://files.hudexchange.info/resources/documents/2018AHAR-Part-1.pdf [Accessed 1 Mar 2020].

33 Ministry of Health, Labor and Welfare. Lifetime experience rate of illegal drugs in major countries, 2017. Available: https://www.mhlw. go.jp/bunya/iyakuhin/yakubuturanyou/torikumi/dl/index-05.pdf [Accessed 1 Mar 2020].

34 Shah R, Chen C, O'Rourke S, et al. Evaluation of care management for the uninsured. Med Care 2011;49:166-71.

35 Murphy SM, Neven D. Cost-Effective: emergency department care coordination with a regional Hospital information system. J Emerg Med 2014;47:223-31.

36 Statistics of Japan, e-Stat: portal site of official statistics of Japan(in Japanese). Available: https://www.e-stat.go.jp/regional-statistics/ ssdsview/municipality [Accessed July 1, 2020] 